\title{
Effect of Rockwool and Steel fiber on the Friction Performance of Brake Lining Materials
}

\author{
Stephen Bernard $\mathrm{S}^{1}$, Jayakumari L S ${ }^{1}$
}

\footnotetext{
${ }^{1}$ Department of Rubber and Plastics Technology, Madras Institute of Technology, Chennai, TamilNadu, India, +919444643685, e-mail: 1sjayakumarimit@gmail.com
}

\begin{abstract}
Wear resistance and Frictional stability are key performance requirements for brake lining. Automotive brake linings are usually made of various ingredients such as binder, filler, friction modifiers and reinforcement. Rockwool is a mineral fiber and steel fiber is a metallic fiber. In this work reinforcement fibers used are both the mineral and metallic fibers with six different composition prepared and tested. The result shows that metallic fibers should be high compared to mineral fiber for best frictional performance and wear resistance. Friction-wear properties of the reinforced samples were investigated on the cast iron disc as a counterpart using a pin on disc wear tester. The investigation confirmed that the sample with increase in steel fiber $(4 \%$, $8 \%$ and $12 \%$ ) improves the wear resistance. On the other hand specimen with high content of Rockwool fiber forms an improper ratio among the other ingredients. The SEM images of the sample indicated that an increase in steel fiber higher than $12 \%$ content resulted in adhesive wear.Analysis of the experimental result shows that the sample with $12 \%$ steel fiber and $8 \%$ Rockwool fiber exhibited the optimum friction-wear behavior. Finally the effect of environment on the composites was investigated in water, salt water and oil.
\end{abstract}

Keywords: Brakes, rolling friction, steel fibre, rockwool fibre, EDS, SEM

\section{INTRODUCTION}

The essential component in a braking system are brake drum (rotating part) and brake lining which is the stationary part to press against the brake drum to slow or stop the rotation [1]. Brake linings are designed to withstand stable, humidity, wear and reliable friction force [2]. Brake friction materials have evolved significantly over the years. They have gone from asbestos to organic to semi-metallic formulations. Each of these materials has proven to have advantages and disadvantages regarding environmental friendliness, wear, noise and stopping capability.

Reinforcing fibers are included in the brake lining to maintain the strength, thermal stability and friction properties $[3,4]$. Fibers in brake lining determine wear stabilization, wear minimization and friction optimization under a dynamic set of operating variables such as braking force, sliding speed, braking duration and braking temperature [5,6]. (commercial brake lining contains $16-20 \%$ of reinforcing fibers [6]).

Along with fibers, binders, fillers, lubricants and abrasive particles are added to improve the friction properties. Among many ingredients, the fiber plays a crucial role in determining the friction properties. Usually brake lining consists of 5-25 vol\% of reinforcing fibrous ingredient which influences the brake achievement [7]. While braking, pads are in direct contact with the braking drum and transfer the pressure of 1.2 $\mathrm{MPa}$ during soft braking and 10 $\mathrm{MPa}$ in extreme condition. steel and copper fibers have a higher strength to withstand the function of direct and sliding contact of the brake drum. The main drawback is that copper decreases the coefficient of friction [8-10].

Rockwool is a type of inorganic fiber which is primarily used in the heat preservation projects in architecture-building, industry and shipbuilding because of the best heat-insulation, sound-insulation, stable chemical capability and incombustibility. Rockwool is a furnace product of molten rock at a temperature of about $1600^{\circ} \mathrm{C}$, through which a stream of air is blown. Braking is to decelerate the velocity of a vehicle, whereas kinetic energy of brake drum is transferred in to thermal energy which is reflected in increasing the temperature of brake lining. Rockwool fiber has a thermal conductivity of $0.045 \mathrm{~W} / \mathrm{mK}$ which will reduce the heat transfer from the drum to pad $[11,12]$. Alumina is the most stable element in the brake lining materi- 
al due to their inherent thermal stability. Cashew friction dust is used to improve friction stability at elevated temperature and it is the organic ingredient which helps to remove the pyrolyzed friction film at the friction interface [10]. Graphite is extremely resistant to heat and highly chemically inert in contact with almost any other material. It is used in brake lining with the need to substitute for asbestos. Antimony trisulfide will ignite at higher temperature and does not react with water at room temperature [13].

Designing friction brake material is often based on experience or a trial and error method to make a new formulation. It has long been claimed as a problem of multistage optimization right from selection of ingredients to processing till reaching at appropriate set of performance criteria [13-17]. In our previous work, there was clear and substantial studied were carried on the effect of Cardanol in phenolic resin binder [18].

A limited number of studies investigating the effect of reinforcement fibers in brake pad materials are available in the literature and complete analysis of the keyrole of reinforcement fiber is seldom found. In this experiment steel and rockwool fiber increased up to $20 \%$ by increasing $4,8,12,16$ and $20 \%$.

\section{EXPERIMENTAL WORK}

\subsection{Materials}

Rock wool fiber (B M marketing and trading pvt. ltd., Chennai), Steel fiber (Ryan international, Mumbai), Cardanol and cashew dust (Satya Cashew chemicals pvt. Itd., Chennai), Phenol formaldehyde (Esterkote pvt. ltd., chennai) and Calcium carbonate, antimony trisulfide, graphite, calcium silicate, alumina and silicon (All from metro scientific company, chennai) were used during investigation.

\subsection{Sample Preparation}

All the ingredients were weighed using an analytical balance instrument and mixed using a blender (electron EBR 100) for $6 \mathrm{~min}$ at $10000 \mathrm{rpm}$ in room temperature $\left(30^{\circ} \mathrm{C}\right)$. Fibers (Steel fibers and Rock wool fiber) were added initially followed by the required quantity of filler (calcium carbonate), abrassive (alumina), lubricants (antimony trisulfide and graphite) and friction modifiers (vermiculate, calcium silicate and cashew dust) added simultaneously. Finally binder material was added [10]. Table 1 shows the ingredients of the friction material investigated in this work. For analyzing hardness, bulk density, compressibility, porosity and wear properties of the specimen, two different molds (size: $150 \times 150 \times 3 \mathrm{~mm}$ and $\varphi 5 \times 32 \mathrm{~mm}$ ) were used for pressing.

Table 1: The ingredients of the friction material investigated in this work

\begin{tabular}{|c|c|c|c|c|c|c|}
\hline Raw Materials ( \% in Weight ) & RF20 & RF16 SF4 & RF12 SF8 & RF8 SF12 & RF4 SF16 & SF20 \\
\hline $\begin{array}{l}\text { Cardanol Phenol Formaldehyde } \\
\text { Resin }\end{array}$ & 20 & 20 & 20 & 20 & 20 & 20 \\
\hline Rockwool fibre & 20 & 16 & 12 & 8 & 4 & 0 \\
\hline Steel fibre & 0 & 4 & 8 & 12 & 16 & 20 \\
\hline $\mathrm{CaCO}_{3}$ & 20 & 20 & 20 & 20 & 20 & 20 \\
\hline $\begin{array}{l}\text { Alumina, Cashew dust, Calcium } \\
\text { Silicate, Vermiculate, Silicon }\end{array}$ & 32 & 32 & 32 & 32 & 32 & 32 \\
\hline Antimony trisulfide, Graphite & 8 & 8 & 8 & 8 & 8 & 8 \\
\hline
\end{tabular}

The die was preheated to $180{ }^{\circ} \mathrm{C}$ and pressure of $160 \mathrm{~kg} / \mathrm{cm}^{2}$ was applied over a mixture for a molding time of $6 \mathrm{~min}$. Molding involves several stages: initial molding, elastic-plastic deformation and particle fracture or fragmentation [14]. During the initial stage, rearrangement of powder particles, which leads to the filling of large voids and the break up of particle bridges. In the elastic-plastic stage, the applied pressure is further increased and plastic deformation occurs locally at the inter particle contact points. In the final stage of molding, plastic deformation becomes widespread, accompanied by shearing, generation of new oxide-free surfaces, cold welding of contacting surfaces and accompanied by reduction in porosity.

Subsequently it is post cured at a constant temperature of $180^{\circ} \mathrm{C}$ by placing the samples 
(Dimension: $150 \times 150 \times 3 \mathrm{~mm}$ and $\varphi 5 \times 32 \mathrm{~mm}$ ) in a preheated furnace for 4 hrs. Because the particles of a material are joined together and gradually reducing the volume of pore space among them, enhances curing uniformity, reduces thermal expansion

\subsection{Test and analysis}

Specimens were sectioned and examined using scanning electron microscope (SEM) model EVO MA15 to determine mixing of friction materials. Prior to SEM evaluation, the specimens are coated with gold using plasma sputtering apparatus Edwards sputter coater model S150B. For the energy dispersive X-ray analysis of the specimen, an Oxford instruments Nanoanalysis INCA Energy 250 Microanalysis system (EDS) was used. The environmental effect of the friction material were determined at room temperature and measured by ASTM D 570-77 standard with water, salt water and SAE 20w-40. Using Rockwell hardness tester hardness of friction material specimen was measured. Bulk density was measured by the water displacement technique using the standard SAE J380. Compressibility measurement was performed using a compression tester and it is obtained from the slope of the height change as a function of applied pressure. The crosshead speed of the machine was kept at $0.5 \mathrm{~mm} / \mathrm{min}$ [18].

A material is tested using pin on disc apparatus which provides automatic acquisition of friction coefficient and wear measurements. It gives stable coefficient of friction once running in phase is achieved. Wear test was conducted using DUCOM wear and friction monitor - TR 20 with grey cast iron as the counter part with a diameter of $120 \mathrm{~mm}$. All the testing procedures were operated by a WinDucom data acquisition system on a computer using the ASTM G-99 standard. The size of a single composite material is $8 \mathrm{~mm}$ diameter and a length of $32 \mathrm{~mm}$. The disc was ground to a smooth surface finish and renewed for each test. The samples were placed on the wear disc and the sliding wear tests were carried out at various time and speed. The test was conducted in a load range of $20 \mathrm{~N}$ at a sliding velocity of $2-4 \mathrm{~m} / \mathrm{s}$ and at sliding distance of $6.3 \mathrm{~km}$. For each specimen the testing time is $2100 \mathrm{~s}$ by varying the speed $(300,500,700 \mathrm{RPM})$ with respect to $700 \mathrm{~s}$. After each test, the specimens were removed, cleaned in acetone and weighed with an electronic balance within an accuracy of $0.1 \mathrm{mg}$. The friction force $(\mathrm{F})$ was continuously monitored during the wear test for determining the coefficient of friction $(\mu)$. The friction force was measured for each pass and then averaged over the total number of passes for each wear test.

\section{RESULTS AND DICUSSIONS}

\subsection{Properties of Composites}

Table 2: Properties of the specimen

\begin{tabular}{lcccccc}
\hline \multicolumn{1}{c}{ Properties } & RF20 & RF16 & RF12 & RF8 & RF4 & RF0 \\
\hline Bulk Density $\left(\mathrm{g} / \mathrm{cm}^{3}\right)$ & 13.3 & 12.6 & 12.1 & 11.8 & 12.3 & 12.7 \\
\hline Compressibility $\left(10^{-3} \mathrm{~mm} / \mathrm{kN}\right)$ & 5.17 & 5.04 & 4.96 & 4.88 & 4.95 & 4.97 \\
\hline Porosity (\%) & 1.66 & 1.72 & 1.87 & 1.94 & 1.91 & 1.92 \\
\hline Hardness (HRB) & 51 & 49 & 46 & 46 & 44 & 43 \\
\hline
\end{tabular}

As seen from the table 2 most of the property such as bulk density, compressibility and porosity (RF20 > RF16 > RF12 > RF0 > RF4 > RF8) decreased slightly and then increased, which is in tune to the literature range [24]. This is due to the reduction of rockwool fiber and increase of metallic fibers. Brake roughness is dependent on porosity [22]. In RF4 and RF0 due to lower content of rockwool fiber porosity decreases. Higher volume of metallic fiber decreases the hardness of the specimen.

\subsection{Wear}

The specific wear rate of the composite as a function of time is shown in figure 1. It was observed that with the progressive increase in the steel fiber content consistently reduces the weight loss and thickness loss of the composite indicating that presence of steel fiber is responsible for wear in the friction material. For instant, highest wear rates were observed for RF20. It indicates that the surplus rockwool fiber appears which form a improper ratios among the other ingredients. Wear is dependent [19] on hardness, thermal stability of the ingredient and integrity of the composite that is mainly determined by the effectiveness of the reinforcement.

In case of SF20 and RF8 SF12 has the lowest wear rate were observed. Although this is a good result in terms of wear resistance, this condition results in higher friction coefficient values which scratch the brake 
drum along the sliding direction [20] and also a portion of compressed layer of lining material is eventually established on the cast iron counterface, forming a film of glaze and some wear particle are produced during the initial bedding in process [21]. Meanwhile RF12 SF8 and RF8 SF12 showed the best wear performance suggesting this type of reinforced sample has longer life. This may be due to metal chips is nearly equal to the mineral fibre which supresses the wear and enhances frictional performances. The improved wear resistance of the friction material is attributed to the inherent wear resistance of steel with rockwool fibre.

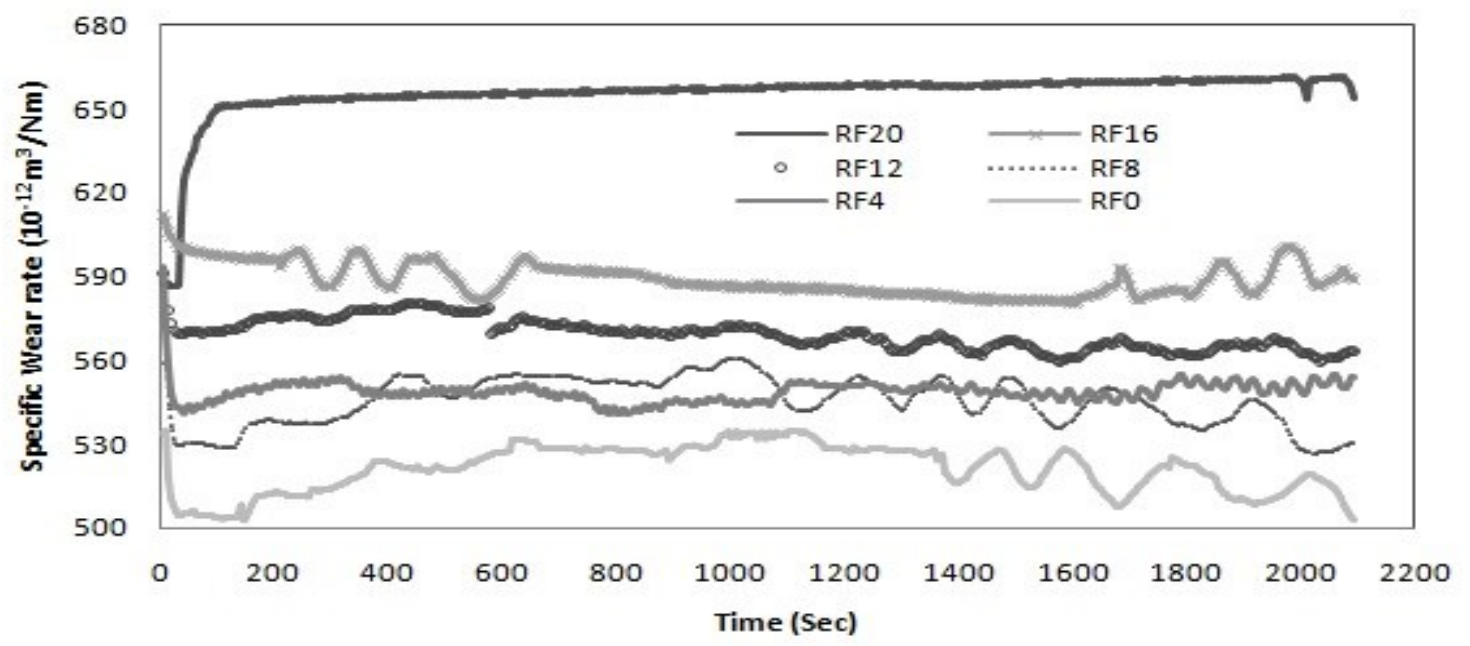

Figure 1: Effect of varying fiber content on Wear properties

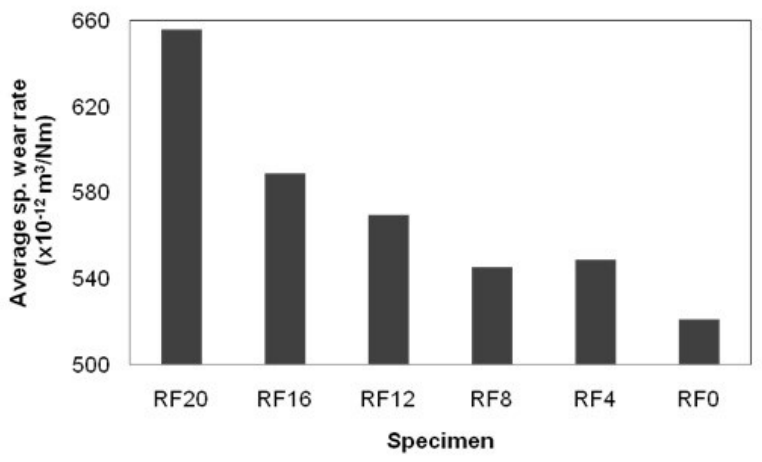

Figure 2: Average specific wear rate as a function of varying fiber content

The average specific wear rate of the specimen with different composition of steel and rockwool fibre is shown in figure 2. From the result it is clear that the highest wear resistance was obtained for SF20 but the friction coefficient decreases for the same specimen. In particular the average specific wear rate of the RF20 specimen was about $10.3 \%$ higher than the RF16 SF4, which indicates that the fade resistance of the material decreased [19]. The specimen with steel fibre $12 \%$ produced a wear resistance high with a good friction coefficient values. This is certainly an interesting result and further investigation is in progress to understand the interaction with other ingredients.

\subsection{Friction stability}

The graphical representation of the time dependency of coefficient of friction (COF) is depicted in figure 3. The addition of rockwool fibre increases the value of friction coefficient. Increase in COF value for the composition of steel fibre higher than $12 \%$ is connected with the chip or particulate structure of steel fibre which reduces the binding strength. RF8 SF12 and RF20 exhibited a relatively stable friction coefficient throughout the entire test. This indicates that a stable friction layer was developed after a short run. Neither judder nor rapid changes of the friction coefficient occured in these specimen [22]. 
SF20 RF0 showed a continous increase in the friction coefficient between 900 and 1600s [20] is often associated with the adhesion of metal chips in the brake lining to the friction surface of the cast iron disc. Except RF4 SF16 and SF20, the COF decreased approximately $8 \%$ during the rotational speed of the counter disc increased by $200 \mathrm{rpm}$. This suggests that the increase in rotational speed of the counterpart affect the friction level for the same composition of the reinforcement [23].

RF16 SF4 showed the sudden loss of friction coefficient in the rotational speed range of 1000-1300 rpm. The drastic decrease of friction coefficient indicates that the rockwool fibre are detached from the binder resin during sliding at higher rotational speed [24]. COF decreased at $300 \mathrm{rpm}$ by increasing steel fiber content $8 \%$; however, in the later stage i.e., at $500 \mathrm{rpm}$ and $700 \mathrm{rpm}$ COF increased. From the figure 4 it is clear that friction coefficient decreases with an increase of rockwool fibre content. This cause a lowering of brake force in the case of higher braking force, therefore, it is undesirable result. In beginning sudden decrease of COF is observed for SF20 due to test conducted before a stable friction layer was developed [25]. The oscillation of COF was higher in this time period.

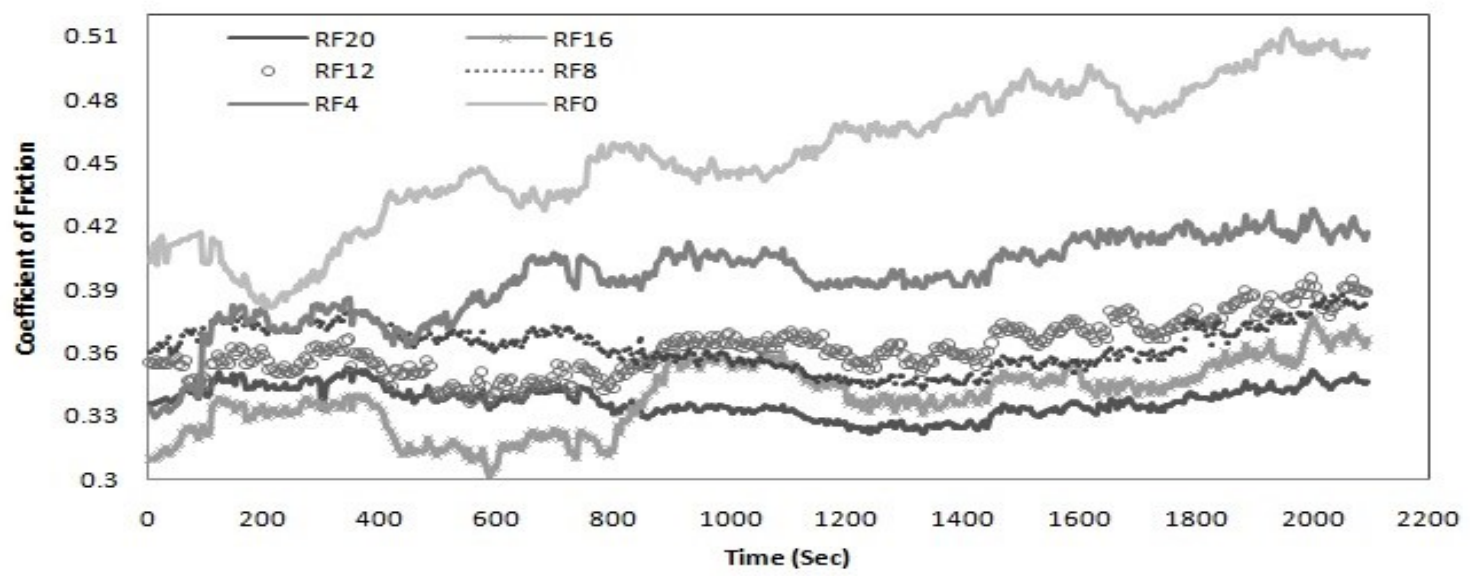

Figure 3: Effect of varying fiber content on Coefficient of Friction

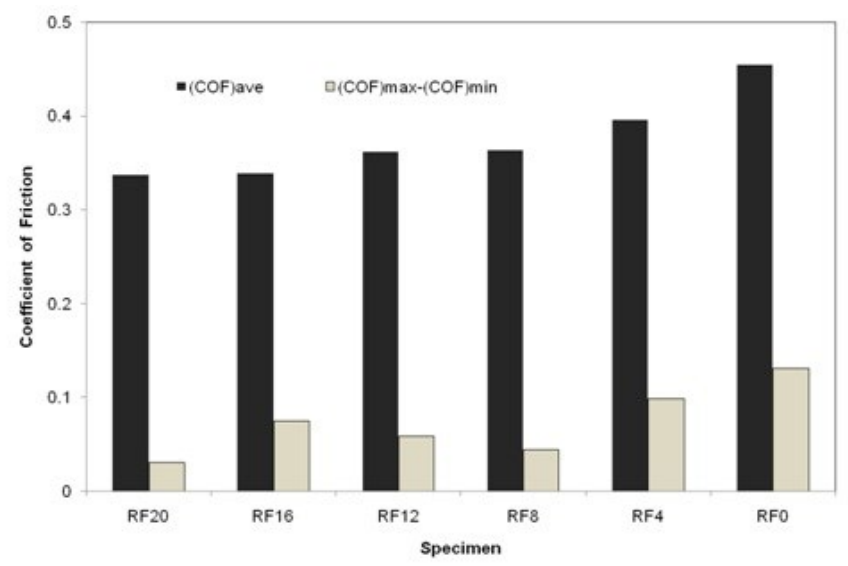

Figure 4: $[\mathrm{COF}]_{\text {avg }}$ and $[\mathrm{COF}]_{\max }-[\mathrm{COF}]_{\min }$ as a function of varying fiber content

Figure 5 shows the average oscillation amplitude of COF with different composite. By using this data the intensity of the oscillation of COF during sliding over a brake drum was examined. It is an important aspect in the brake performance since the noise propensity and brake roughness are directly associated with the friction force oscillation during braking. The curve shows that when speed is increased on the grey cast iron disc, the oscillation amplitude of the friction coefficient is decreased for both steel and rockwool fibre.

Oscillation amplitude of COF is high for SF20 and a sudden drop is observed when the amount of SF is reduced. This result suggest that steel fibre is an important parameter among SF and RF for sensitivity of COF during sliding contact between the pad and disc. 


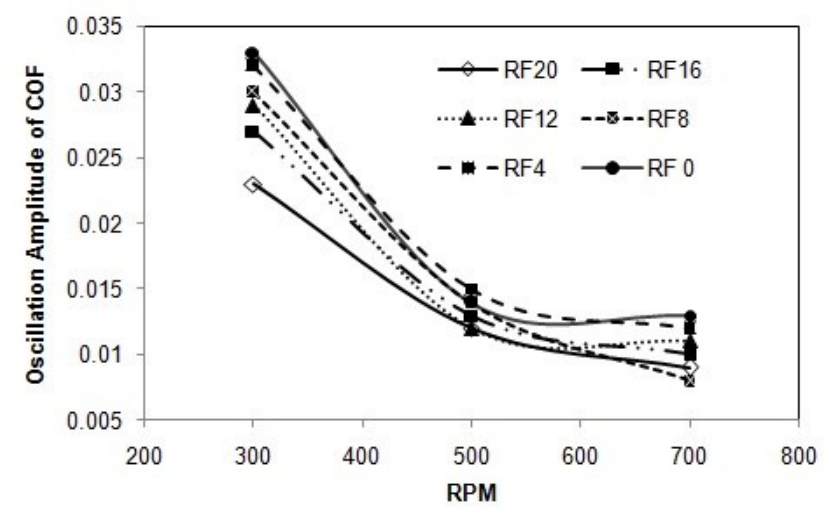

Figure 5: Effect of oscillation amplitude of COF as a function of RPM

\subsection{Microstructural Characteristics}
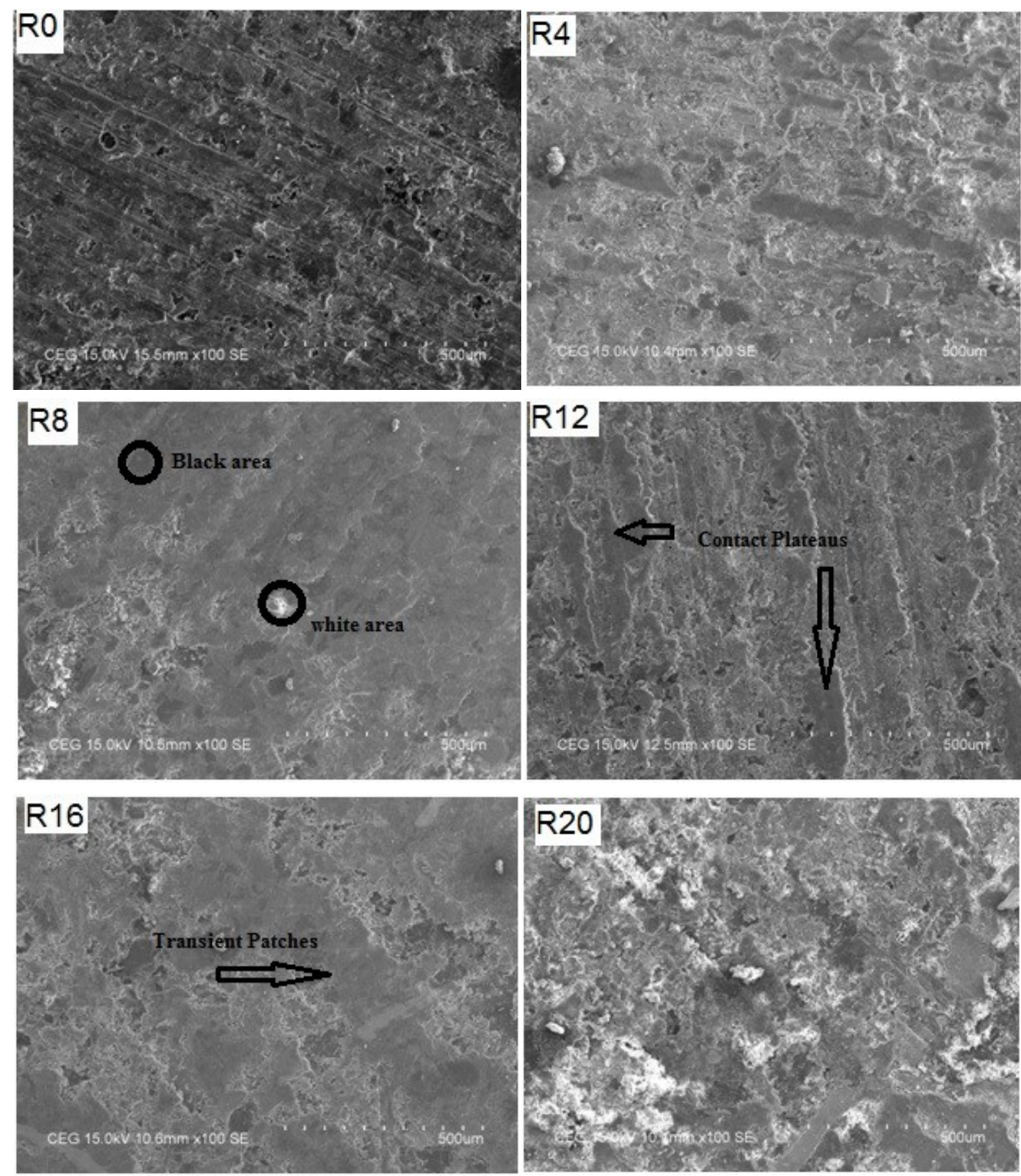

Figure 6 (a,b,c,d,e and f): SEM images taken from the specimen after the wear test on varying fibre content. 
The wear surface of the sample after the friction test were observed using an SEM with energy dispersive Xray analysis is shown in figure $6(\mathrm{a}-\mathrm{f})$. The SEM images show when the steel fibre particles were less in content, they were easily released from the lining surface. On the other hand when the steel fibre content is increased, the fibres were firmly bound in the resin and tended to abrade the disc, resulting in less wear amount in lining surface. Interesting aspect for RF8 SF12 and RF12 SF8 lining surface were not tending to damage even though the rotational speed of the disc is increased.

The thick friction layer is developed on the surface of RF8 SF12. It indicates that the friction layer covering the friction surface diminishes the abrasive effect of the glassy phase by eliminating the sharp edges of the composite and smoothening the friction surface [24].

The figure shows larger contact plateaus in the case of specimen RF12 SF8 while transient patches are observed in RF8 SF12. The contact plateaus form the real contact area in developing friction forces. The primary contact plateaus are formed due to the low removal rate of wear resistant RF12 specimen. The contact plateaus are formed due to wear debris and a gap between the specimen and the cast iron disc. The dimensions and composition of those plateaus includes a vital influence on the frictional stability of the specimen [26]. These imperfect contact areas enable smaller particles to pass between plateaus. In RF12, secondary contact plateaus are formed by thin solid film generated as a consequence of sliding contact that is adhered on its parent worn surface with sintered debris. When the applied pressure is reduced large portions of these solid film areas peel off in flakes [28]. It is seen that the smaller micro voids occurred in the sample having larger rockwool fibre. The larger size micro voids are observed in the increase of steel fibre particles after the friction test. This is due to the loosening of the metallic particles during the friction and it indicates that metal-component coherent surface is larger, friction and wear will be increased [27].

Figure 7 shows the EDS analysis result taken from the black areas of the RF8 SF12 specimen while figure 8 shows the EDS analysis result taken from white areas of the same specimen. From both analyses it is observed that all the chemical elements are present in black and white areas except potassium which is not related to steel and rockwool fibres. It indicates that steel and rockwool fibres are homogeneously mixed throughout the specimen.

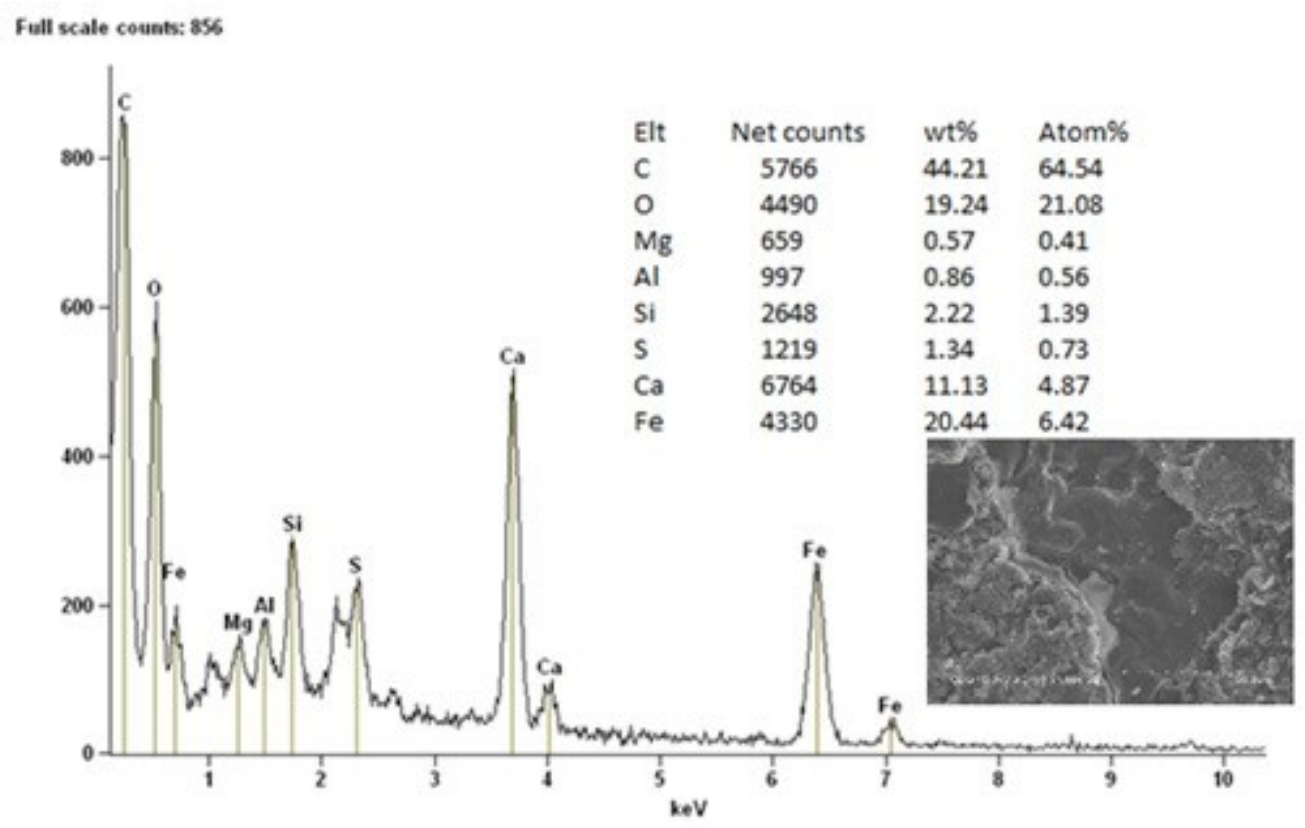

Figure 7: EDS analysis result taken from the black areas of the R8 specimen 


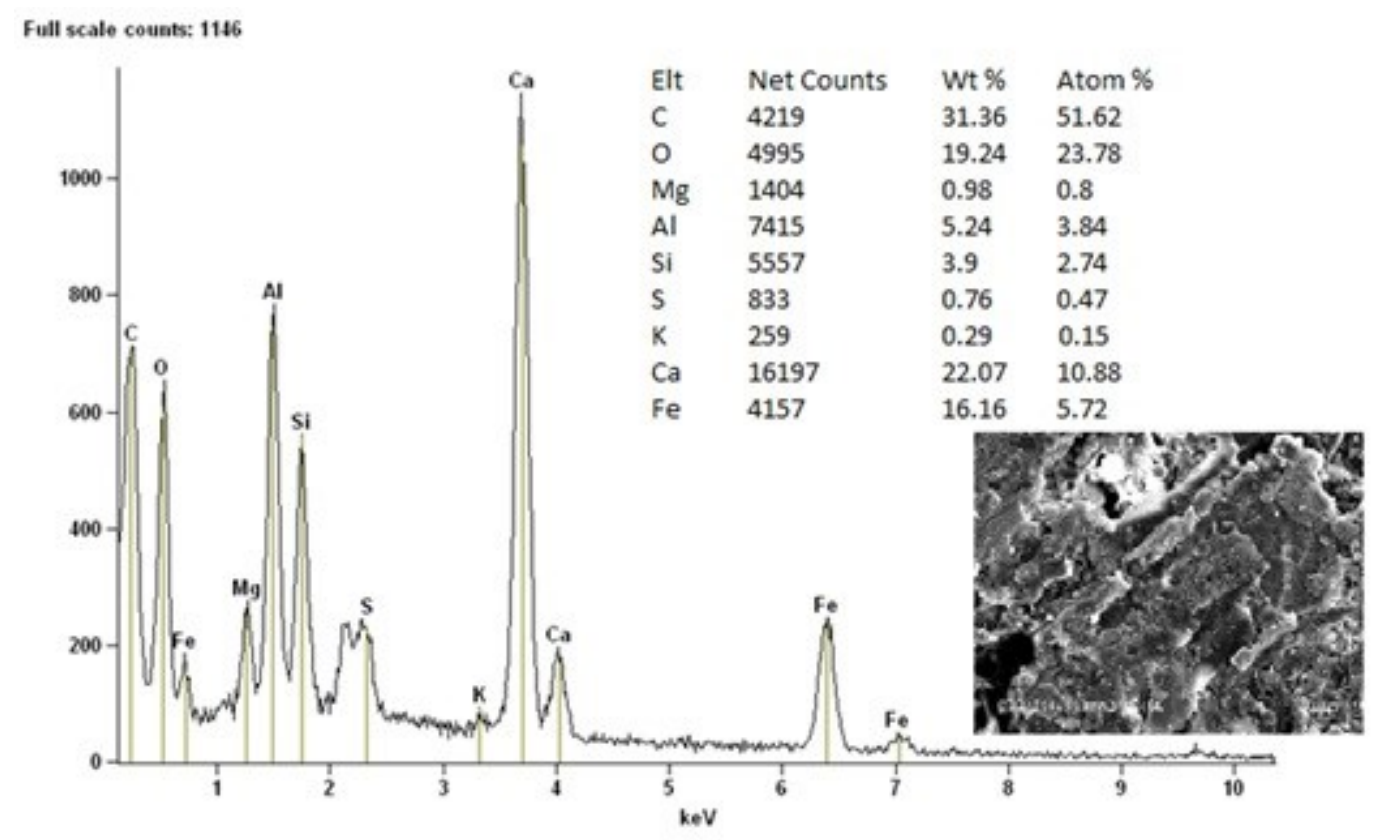

Figure 8: EDS analysis result taken from the white areas of the R8 specimen

\subsection{Environmental effect}

Table 3: The Variation of weight for each sample in water, salt water and oil

\begin{tabular}{cccc}
\hline Specimen & $\begin{array}{c}\text { Water } \\
\text { wt (\%) }\end{array}$ & $\begin{array}{c}\text { Salt Water } \\
\text { wt (\%) }\end{array}$ & $\begin{array}{c}\text { Oil } \\
\text { wt (\%) }\end{array}$ \\
\hline RF20 & 3.284 & 5.371 & 6.197 \\
\hline RF16 & 2.943 & 4.176 & 7.231 \\
\hline RF12 & 3.782 & 4.97 & 5.316 \\
\hline RF8 & 3.146 & 5.138 & 5.684 \\
\hline RF4 & 2.374 & 4.376 & 6.236 \\
\hline RF0 & 2.828 & 4.241 & 6.197 \\
\hline
\end{tabular}

It is seen that variation of mass for each sample has been obtained for different environmental conditions after the wear test is tabulated in table 3. COF value is higher for the specimen SF20, though there is smaller absorption of water in this specimen compared to other specimen. It is clearly noted that when the quantity of rockwool fibre is high, it increases the absorption of water, salt water and oil. It is mostly related to the permeability of fibre and a lower degree of resistance to all naturally occurring chemical, biological and environmental factors. For all specimen absorption of oil is high compared to water and salt water. RF8 SF12 with absorption of oil has only $9 \%$ increase compared to salt water. Environmental test reveals some more interesting phenomenon that reinforcing fibres were not influenced absorption of oil much higher as like other ingredients.

\section{CONCLUSION}

The effect of reinforcement on the friction characteristics, mechanical properties and its morphology were investigated using six friction materials. Friction characteristic such as wear resistance, coefficient of friction, oscillation amplitude of COF were measured by using win ducom friction tester. The conclusion from this work can be summarized as follows.

1. The friction coefficient is dependent on both steel and rock wool fiber. More than $12 \%$ of steel fiber increases the value of COF higher than 0.45 which affects the performance of braking.

2. A greater oscillation amplitude of COF was observed with high steel fiber content due to chip formation or particulate structure of steel fiber. Bulk density, compressibility and porosity increased in RF4 and 
RF0 due to large content of steel fiber. Hardness decreases consistently when a rockwool fiber is smaller in content.

3. On the other hand wear resistance has been observed to decrease consistently with an increase in rock wool fiber. The specimen with steel fiber $12 \%$ produced a high wear resistance with a good friction coefficient values.

4. Addition of rock wool fiber may lead to smaller size microvoids, however larger size microvoid strongly depend on increase of steel fiber. Larger contact plateaus are formed in RF12 while transient patches are observed in RF8.

The result summarized above suggest steel and rockwool fibre combination for the best tribological properties used for brake lining application are $12 \%$ steel fibre and $8 \%$ rockwool fibre which could potentially lead to an optmized overall performance.

\section{ACKNOWLEDGEMENTS}

Author gratefully acknowledge the support of machine design section, IIT Madras for allowed to use DUCOM wear and friction monitor - TR 20 instrument and Madras Institute of Technology for their help in making friction materials and conduct testing.

\section{BIBLIOGRAFIA}

[1] HEE, K.W., FILIP P. "Performance of ceramic enhanced phenolic matrix brake lining materials for automotive brake linings", Wear, v. 259, pp. 1088-1096, 2005.

[2] ARNAB, GANGULY, RAJI, GEORGE, “Asbestos free friction composition for brake linings”, Bulletin material science, v. 31, pp. 19-22, 2008.

[3] MORSHED, M.M., HASEEB, A.S.M.A., "Physical and chemical characteristics of commercially available brake shoe lining materials: a comparative study", Journal of Materials Processing Technology, v.156156, pp. 1422-1427, 2004.

[4] SHARIFAH, H. A., MARTIN, P. A., "The effect of alkalization and fibre alignment on the mechanical and thermal properties of kenaf and hemp bast fibre composites: part 2 - cashew nut shell liquid matrix", Composites Science and Technology, v.64, pp. 1231-1238, 2004.

[5] ARCHANA, D., DEEPAK, S., "Studies on the blends of cardanol-based epoxidized navolac resin and CTPB”, European Polymer Journal, v.43, pp. 2422-2432, 2007.

[6] PAPADOPOULOU, E., CHRISSAFIS, K., "Thermal study of phenol formaldehyde resin modified with cashew nut shell liquid", Thermochimica Acta, v. 512, pp. 105-109, 2011.

[7] MWAIKAMBO, L.Y., ANSELL, M.P., "Hemp fibre reinforced cashew nut shell liquid composites", Composites Science and Technology, v.63, pp. 1297-1305, 2003.

[8] RYOHEI, I., HOZUMI, T., HIROSHI, U., et al, "Synthesis and curing behaviors of a crosslinkable polymer from cashew nut shell liquid", Polymer, v. 43, pp. 3475-3481, 2002.

[9] MINAKSHI, S., RAI, JSP., DEEPAK, S. "Process modeling,optimization and analysis of esterification reaction of cashew nut shell liquid (cnsl)-derived epoxy resin using response surface methodology", Journal of Hazardous Materials, v. 185, pp. 1198-1204, 2011.

[10] UEXKULL, O.V., SKERFVING, S., DOYLE, R. “Antimony in brake pads-a carcinogenic component? ", Journal of Cleaner Production, v. 13, pp. 19-31, 2005.

[11] AMAR, PATNAIK., MUKESH, K., BHABANI, K.S., et al, "Performance sensitivity of hybrid phenolic composites in friction braking: Effect of ceramic and aramid fibre combination”, Wear, v. 269, pp. 891-899, 2010.

[12] JANG, H., LEE, J.S., FASH, J.W., "Compositional effects of the brake friction material on creep groan phenomena”, Wear, v. 251, pp. 1477-1483, 2001.

[13] CHO, M.H., KIM, S.J., BASCH, R.H., et al., "Tribological study of gray cast iron with automotive brake linings: The effect of rotor microstructure", Tribology International, v. 36, pp. 537-545, 2003.

[14] GURUNATH, P.V., BIJWE, J., "Friction and wear studies on brake-pad materials based on newly developed resin”, Wear, v. 263, pp. 1212-1219, 2007.

[15] ERTAN, R., YAVUZ, N. "An experimental study on the effects of manufacturing parameters on the tribological properties of brake lining materials", Wear, v. 268, pp. 1524-1532, 2010. 
[16] CHO, M.H., KIM, SEONG, J., KIM, D. "Effects of ingredients on tribological characteristics of a brake lining: an experimental case study”, Wear, v. 258, pp. 1682-1687, 2005.

[17] BIJWE, J., ARANGANATHAN, N., SHARMA, S. "Nano-abrasives in friction materials-influence on tribologicalproperties", Wear, v. 296, pp. 693-701, 2012.

[18] STEPHEN BERNARD, S., JAYAKUMARI, L.S., "Effect of the Properties of Natural Resin Binder in a High Friction Composite Material”, Polímeros, v. 24, pp. 149-152, 2014.

[19] KIM, Y. C., CHO, M. H., KIM, S. J. et al, "The effect of phenolic resin, potassium titanate, and CNSL on the tribological properties of brake friction materials", Wear, v.264, pp. 204-210, 2008.

[20] EL-TAYEB, N.S.M., LIEW, K.W., "Effect of water spray on friction and wear behaviour of noncommercial and commercial brake pad maerials", Journal of Materials Processing Technology, v. 208, pp. 135$144,2008$.

[21] CHO, K.H., CHO, M.H., KIM, S.J., et al, "Tribological properties of Potassium Titanate in the brake friction materials; Morphological effects”, Tribology Letters, v.32, pp. 59-66, 2008.

[22] MATEJKA, V., LU, Y., MATEJKOVA, P., et al., "Possible stibnite transformation at the friction surface of the semi-metallic friction composites designed for brake linings", Applied Surface Science, v. 258, pp. 1862-1868, 2011.

[23] MUTLU O. E., FINDIK, F., "Tribological properties of some phenolic composites suggested for automotive brakes", Tribology International, v. 39, pp. 317-325, 2006.

[24] BLAU, P.J., BRIAN, C. J., "Wear of truck brake lining materials using three different test methods", Wear, v. 259, pp. 1022-1030, 2005.

[25] BOZ, M., KURT, A. "The effect of $\mathrm{Al}_{2} \mathrm{O}_{3}$ on the friction performance of automotive brake friction materials”, Tribology International, v. 40, pp. 1161-1169, 2007.

[26] DAVIM J. P., CARDOSO, R. "Tribological Behaviour of the Composite PEEK-Cf30 at dry Sliding against steel using statistical techniques”, Material And Design, v. 27, pp. 338-342, 2006.

[27] CHO, K.H., JANG, H., HONG, Y.S., et al., "The size effect of zircon particles on the friction characteristics of brake lining materials”, Wear, v. 264, pp. 291-297, 2008.

[28] BEZZAZI, M., KHAMLICHI, A., JABBOURI, A., et al., "Experimental characterization of frictional behaviour of clutch facings using Pin-on-disk machine”, Material and Design, v. 28, pp.2148-2153, 2007. 